BMJ Open

Sport \&

Exercise

Medicine

\title{
Metabolic equivalents fail to indicate metabolic load in post-myocardial infarction patients during the modified Bruce treadmill walking test
}

\author{
K Woolf-May, ${ }^{1}$ S Meadows, ${ }^{2}$ D Ferrett, ${ }^{1}$ E Kearney ${ }^{3}$
}

To cite: Woolf-May K, Meadows S, Ferrett D, et al. Metabolic equivalents fail to indicate metabolic load in post-myocardial infarction patients during the modified Bruce treadmill walking test. BMJ Open Sport Exerc Med 2017;2: 000173 .

doi:10.1136/bmjsem-2016000173

- Prepublication history is available. To view please visit the journal (http://dx.doi.org/ 10.1136/bmjsem-2016-

000173).

Accepted 31 January 2017

\section{SLinked}

- http://dx.doi.org/10.1136/ bmjsem-2016-000172

\section{CrossMark}

\begin{abstract}
${ }^{1}$ Human and Life Sciences, Canterbury Christ Church University, Canterbury, UK ${ }^{2}$ School of Sport \& Exercise Sciences, University of Kent at Medway, Canterbury, UK ${ }^{3}$ East Kent Hospital University NHS Foundation Trust, Canterbury, UK
\end{abstract}

Correspondence to Dr K Woolf-May; kate.woolfmay@canterbury.ac.uk

\section{ABSTRACT}

Aim: To investigate the suitability of metabolic equivalents (METs) for determining exercise intensity in phase-IV post-myocardial infarction (MI) men during the modified Bruce treadmill walking test (MBWT). Methods: Twenty phase-IV post-MI men (mean \pm SD, aged $64.4 \pm 5.8$ years) and 20 healthy non-cardiac male controls (59.8 \pm 7.6 years) participated. Participants performed a MBWT. Throughout the participants' heart rate (HR), heart rhythm, expired air parameters and ratings of perceived exertion (RPEs) were measured. MET values were compared between groups and those currently ascribed to each stage of the MBWT.

Results: General linear model analysis found no significant differences between groups during the MBWT for $V_{2}, \mathrm{VCO}_{2}$, HR, METs or RPEs (Borg 6-20 scale). Ascribed METs did not differ from mean METs of post-Mls or controls other than at stage 5 where post-MI METs were significantly lower. Irrespective, the post-MI group worked at a higher percentage of their anaerobic threshold (AT) (respiratory exchange ratio, $\mathrm{RER}=1.0)\left(F_{(2,5)}=7.22, \mathrm{p}<0.008\right)$, higher $\mathrm{RER}$ $\left(F_{(2,5)}=11.25, p<0.001\right)$ with increased breathing frequency $\left(F_{(2,5)}=7.22, p<0.001\right)$. Regression analysis revealed AT to be $\mathrm{VO}_{2} 25.6(\mathrm{~mL} / \mathrm{kg} / \mathrm{min})$ for post-MI versus $\mathrm{VO}_{2} 31.1(\mathrm{~mL} / \mathrm{kg} / \mathrm{min})$ for controls. Gross energy expenditure $(\mathrm{kcal} / \mathrm{min})$ was greater for the postMI group compared with controls $\left(F_{(2,5)}=11.22\right.$, $\mathrm{p}<0.001)$. Throughout the MBWT, post-MI group worked at a higher \%AT/MET than controls $\left(F_{(2,196)}=211.76, \mathrm{p}<0.01\right)$. Body composition did not strongly influence \%AT/MET, parameters of $\mathrm{VO}_{2}$, METs or RPE.

Conclusion: During the MBWT, post-MI men worked more anaerobically per MET (\%AT/MET) than controls. Therefore, current METs based on non-cardiac individuals appear unsuitable in determining the full metabolic load of the exercise intensity for cardiac patients during the MBWT.

\section{INTRODUCTION}

The graded modified Bruce treadmill walking test (MBWT) protocol ${ }^{1}$ is internationally employed in clinical situations to determine the exercise intensity at which a cardiac patient achieves their ischaemic

\section{What are the new findings?}

- Phase-IV post-myocardial infarction (MI) men work at a higher percentage of their anaerobic threshold per metabolic equivalent (MET) than non-cardiac individuals during the modified Bruce treadmill walking test (MBWT).

- Current MET values underestimate the metabolic load (exercise intensity) of phase-IV post-MI men during the MBWT.

- The subjective term 'slightly breathless, slightly sweaty' appears to be achieved at around $43 \%$ of anaerobic threshold (RER=1.0) for both post-MI men and non-cardiac controls.

threshold. $^{2-5}$ The MBWT results are also frequently used to estimate a patient's functional capacity and risk stratification, and/or to assist those in cardiac rehabilitation (CR) in prescribing exercise of an appropriate intensity. Each stage of the test is aligned with a metabolic equivalent (MET), which is a multiple of 1 MET, estimated to be around $3.5 \mathrm{~mL} \mathrm{O} / \mathrm{kg} / \mathrm{min}$ of resting oxygen uptake $\left(\mathrm{VO}_{2} \mathrm{~mL} / \mathrm{kg} / \mathrm{min}\right)$. METs were originally devised to allow easy prescription of exercise and estimation of energy expenditure of various physical activities for the general public, and tables were produced providing MET values over a range of activities. ${ }^{6}$ For most adults, the multiples of the resting 1 MET value appear to be reasonably appropriate. However, over time there has been increasing concern that METs are being used too specifically and are unsuitable for use on certain populations, ${ }^{8-14}$ one example being those with cardiac disease. ${ }^{11}$ ${ }^{12}$ Ainsworth et al, ${ }^{6}{ }^{7}$ who devised the MET tables, readily state that for extremely overweight and underweight individuals current MET values may be inappropriate, and it has been suggested that adjustments are required for cardiac patients. ${ }^{15}$ Taking 
these issues into account, the primary aim of this present study was to investigate whether current METs were suitable for determining exercise intensity in post-myocardial infarction (MI) men during the MBWT when compared with non-cardiac controls, as well as METs ascribed to each stage of the MBWT. Secondary aims were to determine if body composition was influential on the MET values achieved at each MBWT stage and whether subjective markers of exercise intensity were related to the MET values.

\section{METHODS}

All methods and processes were approved by the NRES Committee South East Coast-Kent, REC reference: 12/LO/1663; IRAS Project No. 111944, and by the Faculty of Social and Applied Sciences REC.

\section{Power and sample size calculations}

Based on a previously observed statistically significant difference in METs of $0.65 \pm 0.51$ between cardiac patients and those with normal heart function during exercise, ${ }^{16}$ using Minitab statistical package (V.17), $\mathrm{n}=15$ participants were required in each group to achieve $90 \%$ power at an alpha of 0.05 . Allowing for potential attrition $n=20$ participants were recruited to each group.

\section{Participant recruitment}

Twenty uncomplicated post-MI men (2.4 \pm 2.0 years since MI) were recruited through community phase-IV CR exercise classes. Twenty non-cardiac, apparently healthy, male volunteers were recruited from the same area through word of mouth and posters. All volunteers were given a Participant Information Sheet and interested individuals were asked to complete a Health and Physical Activity Screening Questionnaire. Post-MI patients were required to be 'uncomplicated,' stable, at phase-IV CR level, taking standard medications (such as statin, beta-blocker, aspirin and ACE inhibitor). Potential controls were to be free of cardiac disease and/or event and/or chronic medical condition and/or taking long-term medications. All participants were required to be non-smoking, to understand the nature of the study, to be between 50 and 75 years of age, to perform similar levels of regular physical activity and to be free from any orthopaedic limitations during exercise. Participants who cleared screening were required to provide written informed consent and written acknowledgement of their participation from their general practitioner (GP). Participants were free to withdraw from the study at any time without providing a reason.

\section{Procedures}

All data were collected in the same BASES Accredited Exercise Laboratory and participants were familiarised by visiting the laboratory, undergoing all testing procedures not more than 10 days prior to actual data collection. All participants were familiarised so that during treadmill walking they could walk without holding onto the handrail. Prior to each testing session, each participant was asked pretest screening questions to ensure they were sufficiently healthy and had adhered to pretest criteria. This required participants to wear appropriate loose clothing, not to eat or drink anything containing caffeine within 2 hours, nor to consume alcohol or to exercise within 24 hours of tests. Those on medications were asked to take these as normal. On arrival, each participant was measured for height (Stadiometer Seca 220, Hamburg, Germany) and body mass (Seca 710), and body mass index (BMI) was derived. Each participant then sat quietly for $10 \mathrm{~min}$ while measures of resting blood pressure (BP; mm Hg) (Yamasu Mercurial Spygmomanometer 605P, Kenzmedico, Japan), heart rate (HR; bpm) and rhythm were recorded (12-lead ECG, Cosmed, Italy). Each participant then lay supine for $10 \mathrm{~min}$ for preexercise measures of resting oxygen uptake $\left(V \mathrm{O}_{2}\right)$, which was not considered a measure of resting metabolic rate. Expired air was collected via a face mask covering the mouth and nose (Hans Rudolph Adult Mask, 8930/8940 Series, Kansas, USA), analysed using an online system (Cosmed Quark b ${ }^{2}$ Cardiopulmonary Exercise Testing System, Rome, Italy). Information was transmitted and recorded instantly. Each participant was not permitted to proceed if any unexpected heart abnormalities were detected and/or if their BP was greater than $180 \mathrm{~mm} \mathrm{Hg}$ systolic and/or $100 \mathrm{~mm} \mathrm{Hg}$ diastolic, or resting HR> $100 \mathrm{bpm} .{ }^{17}{ }^{18}$ After clearing screening and briefing, each participant signed informed consent, after which they were measured for body composition by whole-body air-displacement plethysmography (Bod Pod, Cosmed Italy), which required sitting in an enclosed capsule for around 5 min wearing close fitting swimwear, after which the participant put on suitable clothing to proceed with the MBWT (table 1). Because phase-IV post-MI patients have shown to cope with treadmill walking speeds of $3.8 \mathrm{mph}$ at $0 \%$ gradient, ${ }^{11}{ }^{12}$ for the purpose of this study testing was terminated at stage 5 (14\% gradient at $3.4 \mathrm{mph}$ ). It was considered that too few post-MI patients would complete any further stages, affecting statistical significance, and therefore any unnecessary physical stress was considered unethical. Throughout, participants were monitored closely, expired air (breath-by-breath), HR and rhythm as described previously. Average of final minute breath-by-breath MET values were used in analysis. Subjective ratings of perceived exertion (RPEs) Borg 6-20 scale $^{19}$ were taken during the final minute of each stage of the test. As another potential subjective marker of intensity, during the MBWT each participant was also requested to indicate the point where they subjectively felt 'slightly breathless and slightly sweaty.' 
Table 1 Incremental stages for the MBWT protocol

\begin{tabular}{|c|c|c|c|c|c|}
\hline \multicolumn{2}{|l|}{ Stage } & \multirow[b]{2}{*}{ Speed $(\mathrm{m} / \mathrm{h})$} & \multirow[b]{2}{*}{ Grade (\%) } & \multirow[b]{2}{*}{ Duration (min) } & \multirow[b]{2}{*}{ Ascribed METs } \\
\hline Modified Bruce & Full Bruce & & & & \\
\hline 1 & - & 1.7 & 0 & 3 & 1.7 \\
\hline 2 & - & 1.7 & 5 & 3 & 2.9 \\
\hline 3 & 1 & 1.7 & 10 & 3 & 4.7 \\
\hline 4 & 2 & 2.5 & 12 & 3 & 7.1 \\
\hline 5 & 3 & 3.4 & 14 & 3 & 10.2 \\
\hline
\end{tabular}

MBWT, modified Bruce treadmill walking test; MET, metabolic equivalent.

The test was terminated at any point when the participant no longer wished to continue, or if the participant experienced or showed signs of undue fatigue, displayed symptoms and produced measures that indicated they had reached or exceeded their exercise tolerance level. The researchers also terminated the test if it was considered dangerous for the participant to continue, for example, if the 12-lead ECG detected changes in cardiac function (particularly ST segment changes) indicative of myocardial ischaemia. The alert was set to inform researchers when ST segment depression of $\geq 1 \mathrm{~mm}$ was detected. This was not used diagnostically but for safety monitoring purposes only. However, any suspected abnormalities were conveyed to the participant and their GP for follow-up. Immediately after the MBWT, the face mask was removed and the participant performed $10 \mathrm{~min}$ self-paced walking cooldown. Following cooldown, the participant was seated and HR and BP were re-checked, ensuring sufficient recovery. $^{20}$

\section{Data analysis}

Statistical analysis using Minitab statistical package V.17 was employed. All measured variables were checked for normal distribution of data. Statistical difference was set at $\mathrm{p}<0.05$ alpha level. An independent samples t-test was employed to determine any baseline differences between the groups and differences between groups at the various data points during the MBWT for the measured variables. Analysis comparing two lines of regression was employed to determine the differences between the trajectories of the various measured factors for the two groups. Pearson's product-moment correlations were conducted to determine any meaningful and significant relationships between the measured factors. The general linear model (GLM) analysis was used to determine the statistical differences between the groups of the various measured factors during the MBWT, with the application of the 'Bonferroni' correction factor, which changed the level of acceptable significance in accordance with the number of data points being taken into account.

All MET values were based on the standard $3.5 \mathrm{~mL}$ $\mathrm{O}_{2} / \mathrm{kg} / \mathrm{min}$. Respiratory exchange ratio (RER), $\mathrm{VCO}_{2} /$ $V \mathrm{O}_{2}=1.0$, was used to describe point of anaerobic threshold (AT) as this has been deemed appropriate when testing cardiac patients where $\mathrm{HR}$ values are unreliable. $^{21}$ The point of AT for each group was calculated using regression equations, post-MI group $\mathrm{VO}_{2}$ $\mathrm{mL} / \mathrm{kg} / \mathrm{min}=23.8+49.4 \mathrm{RER}$, and controls $V \mathrm{O}_{2} \mathrm{~mL} / \mathrm{kg} /$ $\min ={ }^{-} 29.6+60.7$ RER. During the MBWT, expired air variables were measured, from which gross energy expenditure and METs were calculated. Energy expenditure was determined using the established equation of $\mathrm{kcal} / \mathrm{LO}_{2} / \mathrm{min}=1.2411 \times \mathrm{RER}+3.8076, \mathrm{R}^{2}=0.9996{ }^{22}$ All data were double-checked for transcript errors.

\section{RESULTS}

\section{Participant characteristics}

There were no statistically significant differences in participant characteristics between the two groups, other than body composition (table 2). Even though the groups were similar in body mass, the post-MI participants displayed a significantly greater BMI, percentage body fat and kilograms of body fat, with a lower percentage of lean body mass (LBM) (table 2).

\section{Medications}

All 20 post-MI patients were taking aspirin, a statin and a beta-blocker, which were found to have no statistically significant effect on any of the measured factors. Post-MI patients were also taking a number of different cardiovascular medications. However, the numbers were too few to calculate any statistical effect on the measured variables (table 3).

\section{Modified Bruce treadmill walking test}

Two post-MI participants were stopped during stage 5 of the MBWT, as one displayed an ST depression of $1.7 \mathrm{~mm}$ and the other an RER of 1.11 , also failing to keep pace and showing increasedbreathlessness. 
Table 2 Participant characteristics at baseline, mean \pm SD (range)

\begin{tabular}{|c|c|c|}
\hline & $\begin{array}{l}\text { Controls } \mathbf{n}=20 \\
\text { Mean } \pm \text { SD (range) }\end{array}$ & $\begin{array}{l}\text { Post-MIs n=20 } \\
\text { Mean } \pm \text { SD (range) }\end{array}$ \\
\hline Age (years) & $59.8 \pm 7.6(51-73)$ & $64.4 \pm 5.8(54-75)$ \\
\hline Body mass (kg) & $80.8 \pm 10.8(58.2-105.6)$ & $84.0 \pm 23.9(65.5-121.5)$ \\
\hline BMI $\left(\mathrm{kg} / \mathrm{m}^{2}\right)$ & $25.0 \pm 1.9(20.7-28.1)$ & $28.0 \pm 4.5(21.7-37.9)^{*}$ \\
\hline$\%$ LBM & $77.5 \pm 6.3(65.6-88.1)^{\star}$ & $71.1 \pm 6.9(59.3-83.4)$ \\
\hline Body fat (kg) & $18.7-6.4(8.6-31.2)$ & $26.1-10.4(10.9-49.5)^{*}$ \\
\hline LBM (kg) & $62.2 \pm 7.5(47.2-76.2)$ & $61.6 \pm 7.1(48.5-73.6)$ \\
\hline \multicolumn{3}{|l|}{ Pre-exercise resting measures } \\
\hline HR (bpm) & $55.4 \pm 8.4(54-76)$ & $57.4 \pm 8.5(55-73)$ \\
\hline $\mathrm{VO}_{2}(\mathrm{~mL} / \mathrm{kg} / \mathrm{min})$ & $3.6 \pm 0.8(2.7-5.5)$ & $3.5 \pm 07(2.5-4.8)$ \\
\hline $\mathrm{VO}_{2}(\mathrm{~L} / \mathrm{min})$ & $0.29 \pm 0.07(0.16-0.49)$ & $0.33 \pm 0.15(0.21-0.92)$ \\
\hline RPP (bpm ×SBP mm Hg) & $7613 \pm 1477$ (5805-11172) & $7828 \pm 1670(5029-11340)$ \\
\hline \multicolumn{3}{|c|}{ Self-reported days per week of physical activity } \\
\hline 30 min sessions at moderate intensity & $3.8 \pm 2.0(0-7)$ & $3.8 \pm 1.9(0-7)$ \\
\hline 20 min sessions at vigorous intensity & $2.5 \pm 1.5(0-5)$ & $2.0 \pm 0.9(0-4)$ \\
\hline
\end{tabular}

*Statistically significantly different at $\mathrm{p}<0.01$ level.

Table 3 Number of cardiovascular medications taken by post-MI patients

\begin{tabular}{ll}
\hline Medication & $\begin{array}{l}\text { Number of post- } \\
\text { MI patients }\end{array}$ \\
\hline Aspirin & 19 \\
\hline Clopidogrel & 4 \\
\hline Warfarin & 1 \\
\hline Beta-blocker & 20 \\
\hline Statin & 20 \\
\hline ACE inhibitor & 17 \\
\hline Angiotensin receptor & 2 \\
antagonist & 1 \\
\hline Alpha-blocker & 1 \\
\hline GTN & \\
\hline
\end{tabular}

GTN, glyceryl trinitrate; MI, myocardial infarction.

$\mathrm{VO}_{2}$ parameters and derived METs

The GLM analysis found no significant differences between the non-cardiac controls and post-MI group during the MBWT for oxygen uptake $\left(V \mathrm{O}_{2}\right)$ $(\mathrm{mL} / \mathrm{kg} / \mathrm{min})$ or $V \mathrm{O}_{2}(\mathrm{l} / \mathrm{min})$, amount of $V \mathrm{CO}_{2}(\mathrm{~mL} / \mathrm{kg} /$ $\min )$ or $\mathrm{VCO}_{2}(\mathrm{~L} / \mathrm{min}), \mathrm{HR}$, METs or subjective RPEs (table 4).

There were no significant differences in mean MET values for the stages of the MBWT between the groups or ascribed MET values. Though during stage 5, postMI participants' MET values were significantly lower $\left(F_{(2,5)}=8.45, \mathrm{p}<0.006\right)($ table 5$)$.

Throughout the MBWT, post-MI participants worked at a higher percentage of their AT $\left(F_{(2,5)}=7.22\right.$, $\mathrm{p}<0.008)$, with increased breathing frequency $(\mathrm{BF})$ (breaths $/ \mathrm{min})\left(F_{(2,5)}=7.22, \mathrm{p}<0.001\right)$ and higher RER $\left(F_{(2,5)}=11.25, \mathrm{p}<0.001\right)$. Gross energy expenditure ( $\mathrm{kcal} / \mathrm{min}$ ) was found to be significantly greater for post-MI participants compared with controls, $\left(F_{(2,5)}=11.22, \mathrm{p}<0.001\right)$ (table 4$)$. AT was calculated to be $V \mathrm{O}_{2} 25.6(\mathrm{~mL} / \mathrm{kg} / \mathrm{min})$ for the post-MI versus control 31.1( $\mathrm{mL} / \mathrm{kg} / \mathrm{min})$. Calculations were also performed to determine the percentage of AT that each participants worked during the MBWT in relation to their MET values (\%AT/MET). This revealed that during the MBWT, post-MI participants worked at a significantly higher \%AT/MET, $\quad\left(F_{(2,196)}=211.76\right.$, $\mathrm{p}<0.01$ ) (figure 1).

Body composition

Analysis found no significant relationship between $\mathrm{VO}_{2}$ $(\mathrm{mL} / \mathrm{kg} / \mathrm{min})$ or METs with body composition. 


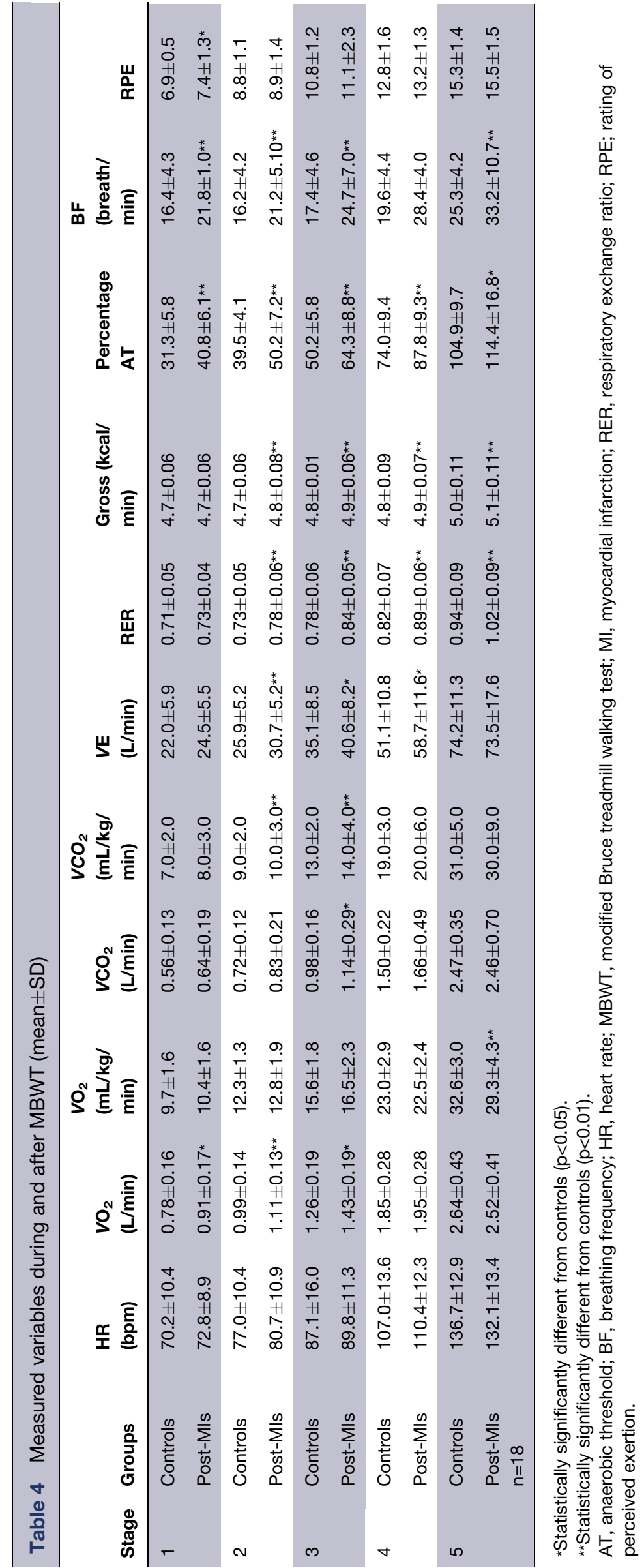


Table 5 Ascribed and achieved MET values during the stages of the MBWT

\begin{tabular}{llll}
\hline Stage & Ascribed METs ${ }^{1}$ & $\begin{array}{l}\text { Non-cardiac controls' METs } \\
\text { Mean } \pm \text { SD }\end{array}$ & $\begin{array}{l}\text { Post-MI patients' METs } \\
\text { Mean } \pm \text { SD }\end{array}$ \\
\hline 1 & 1.7 & $2.7 \pm 0.1$ & $3.0 \pm 0.5$ \\
2 & 2.9 & $3.5 \pm 0.5$ & $3.7 \pm 0.5$ \\
3 & 4.7 & $4.7 \pm 0.7$ & $4.6 \pm 0.7$ \\
4 & 7.1 & $6.6 \pm 0.5$ & $6.6 \pm 0.7$ \\
5 & 10.2 & $9.5 \pm 0.9$ & $8.5 \pm 1.1^{*}$ \\
\hline
\end{tabular}

*Statistically significantly different from ascribed MET values at $p<0.01$.

MBWT, modified Bruce treadmill walking test; MET, metabolic equivalent; MI, myocardial infarction.

However, percentage LBM was inversely associated with $\mathrm{BF}\left(F_{(2,5)}=6.71, \mathrm{p}<0.01\right)$ and positively associated with $V_{2}(\mathrm{~L} / \mathrm{min}) \quad\left(F_{(2,5)}=8.88, \mathrm{p}=0.003\right)$. Increased body mass $(\mathrm{kg})$ also resulted in enhanced production of $V \mathrm{CO}_{2}(\mathrm{~L} / \mathrm{min})\left(F_{(2,5)}=18.43, \mathrm{p}<0.01\right)$. Other measures of body composition did not reach the level of statistical significance.

Secondary analysis performed using GLM with LBM as a covariate showed LBM was not sufficiently strong to influence the significant increased BF in the post-MIs; thus, indicating LBM alone was not the only contributing factor. Correlations also show stronger relationships in relation to the increased $\mathrm{BF}$ during the MBWT than LBM $(R=-0.312, \mathrm{p}=0.001)$, such as RER $(R=0.523, \mathrm{p}=0.001), \operatorname{RPE}(R=0.430, \mathrm{p}=0.001), V \mathrm{CO}_{2}$ $(\mathrm{L} / \mathrm{min}) \quad(R=0.431, \quad \mathrm{p}=0.001), \quad V \mathrm{CO}_{2} \quad(\mathrm{~mL} / \mathrm{kg} / \mathrm{min})$ $(R=0.441, \mathrm{p}=0.001)$ and gross $(\mathrm{kcal} / \mathrm{min})(R=0.523$, $\mathrm{p}=0.001)$.

\section{Perceived exertion}

Post-MIs were found to reach the subjective point of 'slightly breathless/slightly sweaty' at a significantly lower $V \mathrm{O}_{2}(\mathrm{~mL} / \mathrm{kg} / \mathrm{min})$ compared with the controls (post-MI, $11.1 \pm 1.6$ vs controls, to $12.6 \pm 2.2 \mathrm{VO}_{2} \mathrm{~mL} / \mathrm{kg} /$ min, $T=2.23, \mathrm{p}=0.033$ ). This corresponded to 13 on the Borg 6-20 RPE scale for the post-MIs and 13.7 for the non-cardiac controls. However, calculations revealed that both groups subjectively reached the point of 'slightly breathless/slightly sweaty' at around $43 \%$ of their respective AT (see above for other RPE results).

\section{DISCUSSION}

Any misrepresentation in the results of the modified Bruce protocol ${ }^{1}$ has the potential for incorrect evaluation of a cardiac patient's health status, as well as unsafe or ineffective exercise prescription. It is therefore important that the value, indices or equation employed to establish the point of functional capacity and/or ischaemia is as precise as possible. The findings of this study however indicate that the ascribed MET values appear to misrepresent the potential metabolic load of exercise for post-MIs during graded exercise. Although post-MI participants were found to produce significantly higher RER values throughout the MBWT, the post-MIs and non-cardiac controls showed no significant differences in $V \mathrm{O}_{2}, V \mathrm{CO}_{2}$, METs, RPE or HR. Yet, the anaerobic component per MET (\%AT/ MET) was significantly greater for the post-MI group. Comparable findings have been found from three other studies, which also compared male phase-IV post-MI patients with non-cardiac controls during graded exercise. ${ }^{12} 2324$ All these studies found no statistically significant difference in $V_{2}(\mathrm{~mL} / \mathrm{kg} / \mathrm{min})$ or derived METs between groups, but upon secondary analysis did show significantly greater \%AT/MET from all post-MI groups, a difference that increased with exercise intensity. ${ }^{24}$ This enhanced \%AT/MET of the post-MIs was found irrespective of study design, mode of exercise or variations between studies in any resulting $V \mathrm{O}_{2}$ parameters and/or subjective markers of exercise intensity, which are discussed in more detail in a twin paper. ${ }^{24}$ These findings strongly indicate that the evaluation of a cardiac patient's $V \mathrm{O}_{2}$ values or derived MET values alone is insufficient in revealing the 'true' exercise intensity at which a cardiac patient is working. This is especially interesting as the cardiac patients in these studies were all of phase-IV CR level; patients who exercise regularly out in the community and arguably some of the physically fittest. Because those with more severe forms of cardiac disease are known to work more anaerobically during exercise, ${ }^{25}$ it is likely that those with more severe cardiac disease will work at an even greater \%AT/MET than shown from the post-MIs of these studies.

\section{$\mathrm{VO}_{2}(\mathrm{~mL} / \mathrm{kg} / \mathrm{min})$-work relationship}

Analysis found no significant difference in mean $\mathrm{VO}_{2}$ values or derived METs between groups, other than post-MI participants showing significantly lower METs than those ascribed for stage 5. Conversely, a study by Woolf-May and Ferrett ${ }^{11}$ found the linear $V \mathrm{O}_{2}$-walking speed relationship to be significantly greater from a group of post-MI men ( $\mathrm{n}=31$, age $63.2 \pm 6.5$ years) compared with a group of non-cardiac controls $(n=19$, age $64.6 \pm 7.5$ years) during the $10 \mathrm{~m}$ flat shuttle walking test. ${ }^{26}$ The findings revealed walking at $4 \mathrm{mph}$ 


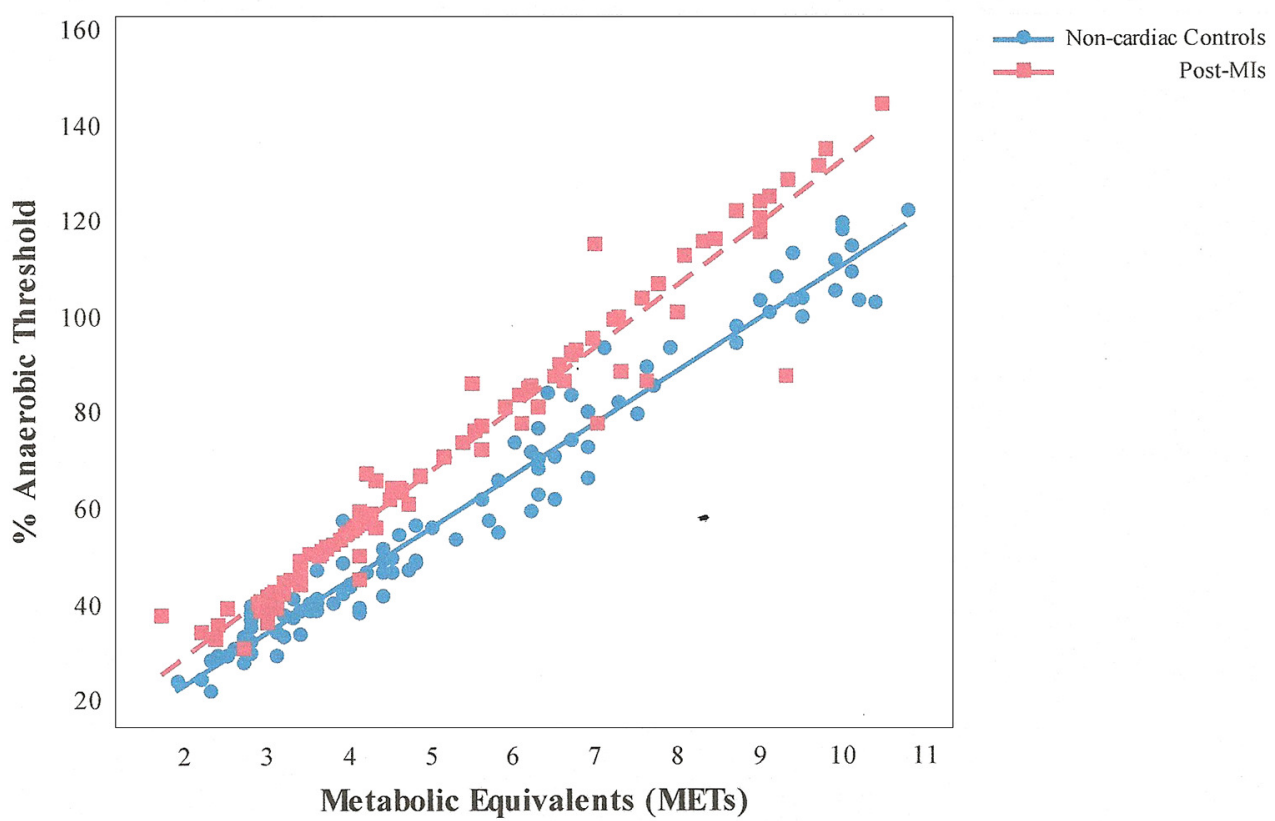

Figure $1 \% A T-M E T$ relationship during the MBWT for post-MI group versus non-cardiac controls. AT, anaerobic threshold; MBWT, modified Bruce treadmill walking test; MET, metabolic eqivalent; MI, myocardial infarction.

was around 6 METs for the non-cardiac controls but nearer 8 METs for the post-MI group. Similarly, a more recent paper from Buckley et $a l^{27}$ observed the $\mathrm{VO}_{2}$-walking speed relationship was up to $30 \%$ greater at the higher stages of a $10 \mathrm{~m}$ shuttle walking test from $\mathrm{n}=32 \mathrm{CR}$ patients in comparison to $\mathrm{n}=30$ age-matched controls. Buckley et $a l^{27}$ found the $V \mathrm{O}_{2}(\mathrm{~mL} / \mathrm{kg} / \mathrm{min})$ linear regression models' underestimated values for cardiac participants, showing the $\mathrm{VO}_{2}$ response to be curvilinear, with the area under the curve being greater in the cardiac group (cardiac $=423 \pm 86 \mathrm{vs}$ control $=316 \pm 52 \mathrm{~mL} / \mathrm{kg} / \mathrm{min} / \mathrm{km} / \mathrm{h}, \quad \mathrm{p}<0.001)$. This therefore brings into question the use of linear $V \mathrm{O}_{2}$ $(\mathrm{mL} / \mathrm{kg} / \mathrm{min})$ based equations in determining exercise intensity in cardiac groups.

\section{$\mathrm{CC}_{2}$ production and body composition}

Regression analysis showed the point of RER $=1.0$ (AT) to be reached sooner at a lower $V \mathrm{O}_{2}$ of 25.6 for postMI participants when compared with $31.1 \mathrm{VO}_{2}(\mathrm{~mL} / \mathrm{kg} /$ $\mathrm{min})$ for the non-cardiac controls. Similar findings have also been reported between phase-IV cardiac patients compared with non-cardiac controls in studies involving shuttle walking, ${ }^{23}$ treadmill walking ${ }^{12}$ and cycle ergometry. ${ }^{24}$ Although the groups in this study were well matched for age, physical activity and body mass, they did however differ in body composition (table 2). Yet, analysis did not find body composition to have any influence on $V \mathrm{CO}_{2}, V \mathrm{O}_{2}$ parameters or METs. In fact, METs were adjusted for cardiac patients to $2.84 \mathrm{~mL} / \mathrm{kg} / \mathrm{min}$ per MET over a range of exercise modes, results showing inconsistent outcomes. This suggested the difference in METs between the groups of post-MI men and their non-cardiac counterparts was not entirely due to body composition. ${ }^{24}$ Furthermore, although the post-MI group displayed a significantly greater gross energy expenditure over the duration of the MBWT than controls, it is unlikely that this was due to differences in body composition between the groups (table 2). Because even though the post-MI group's BMI was significantly greater, the controls had significantly more LBM, and lower per cent body fat and kilogram of body fat, with both groups showing no significant difference in body mass. Therefore, the controls would appear to have relatively more 'active' tissue with the potential for using more energy. Secondary analysis of our data did however indicate that body composition was a possible contributor to the increased $V \mathrm{CO}_{2}$ production and increased $\mathrm{BF}$, where the greater the LBM the lower the $\mathrm{BF}$ and $V \mathrm{CO}_{2}$ production. Nonetheless, further analysis revealed LBM was still not statistically strong enough to eliminate the significant impact of $V \mathrm{CO}_{2}$ production upon the increased BF seen in the post-MI group.

\section{Ratings of perceived exertion}

A secondary aim of the study was to determine how subjectively the participants rated their exercise intensity in relation to the physiological markers and METs. Our findings revealed that during the MBWT, the unvalidated subjective point of 'slightly breathless, slightly sweaty' was achieved around $43 \%$ of AT for both groups, yet at this point post-MIs reported a lower RPE of 13.0, while the controls reported 13.7. A study by Scherr et $a l^{28}$ comparing graded exercise RPE values of coronary artery disease $(\mathrm{CAD})$ patients $(\mathrm{n}=146$, mean age 66 years, BMI 26.7 and 2 hours of weekly exercise) with non-cardiac participants $(\mathrm{n}=2560)$, using the Borg $6-20$ 
scale, ${ }^{19}$ showed CAD patients significantly under-rated RPE at blood lactate values of 3.0 and $4.0 \mathrm{mmoL} / \mathrm{L}$ compared with non-cardiac controls $(3 \mathrm{mmoL} / \mathrm{L}$ : CAD, $12.0 \pm 1.7 \mathrm{vs}$ total cohort, $13.0 \pm 1.9 \mathrm{RPE}, \mathrm{p}<0.001$; $4 \mathrm{mmoL} / \mathrm{L}: \quad \mathrm{CAD}, \quad 14.0 \pm 1.7 \mathrm{vs}$ total cohort, 14.2 \pm 1.9 RPE, $\mathrm{p}<0.01)$. Forti ${ }^{29}$ also found male CAD patients (mean age 56 years, $n=10$, taking beta-blockers, and $n=10$, not taking beta-blockers) to report significantly lower RPE values (Borg CR 10 scale) ${ }^{30}$ during cycle ergometry compared with $n=10$ noncardiac patients (RPE: 4.9, 5.9 and 6.5, respectively). Additionally, Joo $e^{2} \mathrm{al}^{31}$ reported there is to be substantial intersubjective variability from $n=11$ cardiac patients (of mix condition and gender taking betablockers) during overground walking at RPE 11-13 ${ }^{19}$ from the 6-20 scale in relation to predetermined $\% V_{2}$ reserve $\left(\mathrm{VO}_{2} \mathrm{R}\right)$. Nine per cent of cardiac patients walked at $<40 \%, \quad 9 \%<40 \%-60 \%$ and $82 \%<60 \% \quad \mathrm{VO}_{2} \mathrm{R}$. Although cardio-selective beta-blockers seem not to affect RPE responses compared with non-cardio-selective beta-blockers, ${ }^{32}$ it has therefore been postulated that different cardio-selectivity beta-blockers may be influential on reporting RPE values. Notwithstanding, secondary analysis of the MET-RPE relationship during the MBWT of this study found no significant differences between the groups in RPE values.

\section{CONCLUSION}

Aligned with other studies, the findings of this study clearly showed post-MI men worked more anaerobically per MET than non-cardiac men during graded exercise, indicating current METs to underestimate the metabolic load of the post-MI patients. Therefore, current METs would appear unsuitable for determining the true exercise intensity of cardiac patients during the MBWT.

Acknowledgements Acknowledgements to statistician Dr Sabina Hulbert for advice and verification of the statistical analysis.

Contributors Dr Woolf-May, Dr Meadows and Mr Kearney developed the research protocol. Dr Meadows, Debbie Ferrett and Anna Upton conducted data collection. Dr Woolf-May conducted data analysis and report writing. Dr Woolf-May, Dr Meadows and Mr Kearney contributed to editing, gaining ethical approval and administrative procedures.

Funding Funding for this study was provided by East Kent Hospital University NHS Foundation Trust Cardiovascular Disease Research Grant Award.

Competing interests None declared.

Provenance and peer review Not commissioned; externally peer reviewed. Data sharing statement Additional data are available upon request.

Open Access This is an Open Access article distributed in accordance with the Creative Commons Attribution Non Commercial (CC BY-NC 4.0) license, which permits others to distribute, remix, adapt, build upon this work noncommercially, and license their derivative works on different terms, provided the original work is properly cited and the use is non-commercial. See: http:// creativecommons.org/licenses/by-nc/4.0/

(c) Article author(s) (or their employer(s) unless otherwise stated in the text of the article) 2017. All rights reserved. No commercial use is permitted unless otherwise expressly granted.

\section{REFERENCES}

1. Bruce RA, Kusumi F, Hosmer D. Maximal oxygen intake and nomographic assessment of functional aerobic impairment in cardiovascular disease. Am Heart J 1973;85:546-62.

2. Noona V, Dean E. Submaximal exercise testing: clinical application and interpretation. Physical Therapy 2002;80:782-807.

3. Fletcher GF, Balady GJ, Amsterdam EA, et al. Exercise standards for testing and training: a statement for healthcare professionals from the American Heart Association. Circulation 2001;104:1694-740

4. Hills J, Timms A. ABC of clinical electro-cardiology tests. exercise tolerance tests. BMJ 2002;324:1085-7.

5. Queensland Health. Exercise stress testing: cardiac science. 1.0: Guideline 2012:1-15.

6. Ainsworth BE, Haskell WL, Leon AS, et al. Compendium of physical activities: classification of energy costs of human physical activities. Med Sci Sports Exerc 1993;25:71-80.

7. Ainsworth BE, Haskell WL, Whitt MC, et al. Compendium of physical activities: an update of activity codes and MET intensities. Med Sci Sports Exerc 2000;32:S498-S516.

8. Morris CK, Myers J, Froelicher VF, et al. Nomogram based on metabolic equivalents and age for assessing aerobic exercise capacity in men. J Am Coll Cardiol 1993;22:175-82.

9. Peterson MJ, Newell S, Beatty C, et al. Comparison of metabolic equivalents between compendium means and a multiple comorbid group during common exercisers. Med Sci Sprts Exerc 2004; 7:310-33.

10. Byrne NM, Hills AP, Hunter GR, et al. Metabolic equivalent: one size does not fit all. J Appl Physiol 2005;99:1112-9.

11. Woolf-May K, Ferrett D. Metabolic equivalents during the 10-m shuttle walking test for post-myocardial infarction patients. $\mathrm{Br} J$ Sports Med 2008;42:36-41.

12. Meadows S, Woolf-May K, Kearney E. Metabolic equivalents for post-myocardial infarction patients during a graded treadmill walking test. J Exerc Physiol Online 2013;16:60-9.

13. Spadano JL, Must A, Bandini LG, et al. Energy cost of physical activities in 12-y-old girls: MET values and the influence of body weight. Int J Obes Relat Metab Disord 2003;27:1528-33.

14. deJong $A$. The metabolic equivalent: re-evaluating what we know about the MET. ACSMs Health Fit J 2010;14:43-6.

15. Savage PD, Toth MJ, Ades PA. A re-examination of the metabolic equivalent concept in individuals with coronary heart disease. $J$ Cardiopulm Rehabil Prev 2007;27:143-8.

16. Solal AC, Chabernaud JM, Gourgon R. Comparison of oxygen uptake during bicycle exercise in patients with chronic heart failure and in normal subjects. J Am Coll Cardiol 1990;16:80-5.

17. American association of cardiovascular and pulmonary rehabilitation (AACVPR). Guidelines for cardiac rehabilitation and secondary prevention programs. Champaign, Illinois: Human Kinetics, 2004

18. British Association of Cardiac Prevention and Rehabilitation (BACPR). The BACPR standards and core components for cardiovascular disease prevention and rehabilitation. 2nd Ed. London: BACPR, 2012.

19. Borg GA. Psychophysical bases of perceived exertion. Med Sci Sports Exerc 1982;14:377-81.

20. Association for Chartered Physiotherapists in Cardiac Rehabilitation (ACPICR). Standards for physical activity and exercise in the cardiac population. http://acpicr.com/publications (accessed 08 Jan 2015).

21. Solberg G, Robstad B, Skjønsberg $\mathrm{OH}$, et al. Respiratory gas exchange indices for estimating the anaerobic threshold. J Sports Sci Med 2005;4:29-36.

22. Péronnet $F$, Massicotte $D$. Table of nonprotein respiratory quotient: an update. Can J Sport Sci 1991;16:23-9.

23. Woolf-May K, Meadows S. Exploring adaptations to the modified shuttle walking test. BMJ Open 2013;3:e002821.

24. Woolf-May K, Meadows S. Appropriateness of the metabolic equivalent (MET) as an estimate of exercise intensity for postmyocardial infarction patients. BMJ Open Sport Exerc Med 2017;2:e000172.

25. Wasserman K, Mcllroy MB. Detecting the threshold of anaerobic metabolism in cardiac patients during exercise. Am J Cardiol 1964;14:844-52.

26. Singh SJ, Morgan MD, Scott S, et al. Development of a shuttle walking test of disability in patients with chronic airways obstruction. Thorax 1992;47:1019-24.

27. Buckley JP, Cardoso FM, Birkett ST, et al. Oxygen Costs of the incremental Shuttle walk Test in cardiac Rehabilitation Participants: An historical and contemporary Analysis. Sports Med 2016;46:1953-62.

28. Scherr J, Wolfarth B, Christle JW, et al. Associations between Borg's rating of perceived exertion and physiological 
measures of exercise intensity. Eur $J$ Appl Physiol 2013;113:147-55.

29. Forti M, Zamunér AR, Kunz VC, et al. Ratings of perceived exertion at anaerobic threshold in patients with coronary artery disease. Fisioterapia e Pesquisa 2014;21:113-9.

30. Borg G. Perceived exertion as an indicator of somatic stress. Scand J Rehabil Med 1970;2:92-8.
31. Joo KC, Brubaker PH, MacDougall A, et al. Exercise prescription using resting heart rate plus 20 or perceived exertion in cardiac rehabilitation. J Cardiopulm Rehabil 2004;24:178-84.

32. Eston R, Connolly D. The use of ratings of perceived exertion for exercise prescription in patients receiving beta-blocker therapy. Sports Med

1996;21:176-90. 